\title{
CONTRIBUIÇÃO DA INICIAÇÃO CIENTÍFICA JÚNIOR NA FORMAÇÃO DOS BOLSISTAS ICJ: REFLEXÕES DE QUESTÕES ÉTNICO-RACIAIS
}

\author{
Mateus Augusto Almeida Martins ${ }^{1}$ \\ Victor Silva Salaroli do Nascimento ${ }^{2}$ \\ Mellina de Fátima Neres de Sousa Curty ${ }^{3}$
}

Resumo: Pretendemos por meio deste artigo analisar a contribuição das pesquisas do Programa de Iniciação Científica Júnior (ICJ) para a formação dos alunos de Ensino Fundamental ( $8^{\circ}$ e $9^{\circ}$ ano) da Escola Estadual de Ensino Fundamental e Médio "Aristeu Aguiar". A partir das aulas teóricas, que tem como objetivo inseri-los melhor na temática abordada pelo projeto, buscou-se trabalhar a história e cultura afrobrasileira a partir de pesquisas bibliográficas, como foco de pesquisa a utilização do jornal O Cachoeirano para caracterizar o escravo por volta do século XIX. Posteriormente, analisaremos como os autores contemporâneos dialogam com a pesquisa histórica sobre a população negra para, assim, discutir com os alunos as divergências e convergências, levando em consideração os dados recolhidos no jornal e as ideias dos autores. Por fim, compararemos a compreensão do conteúdo, anterior ao início da pesquisa e posterior, considerando o conteúdo visto pelos alunos na instituição de ensino ao qual eles pertencem. Pôde-se perceber que as metodologias utilizadas, tanto nas aulas teóricas como nas pesquisas, foram suficientes para o aprendizado dos alunos acerca do tema proposto e abordado no projeto.

Palavras-chave: Iniciação Científica Júnior; História e cultura afro-brasileira; O Cachoeirano.

\footnotetext{
${ }^{1}$ Faculdade de Filosofia, Ciências e Letras de Alegre - FAFIA, Brasil. E-mail: m_ateusaugusto@hotmail.com.

2 Faculdade de Filosofia, Ciências e Letras de Alegre - FAFIA, Brasil. E-mail: victorsalaroli26@gmail.com.

${ }^{3}$ Faculdade de Filosofia, Ciências e Letras de Alegre - FAFIA, Brasil. E-mail: mell.curty@gmail.com.
} 